\title{
MARX, EL ESPACIO GEOGRÁFICO Y EL ESTADO
}

Marx, the geographic space and the State/ Marx, o espaço geográfico e o estado

Flabián Nievas ${ }^{1}$

\section{RESUMO}

Este artigo pretende ser uma modesta contribuição para a antiga e nunca completamente resolvida controvérsia sobre o papel do espaço na teoria de Marx, entendendo que há, implicitamente, uma poderosa análise do espaço geográfico nos dois últimos capítulos do primeiro volume de "The capital". Parece haver uma tensão entre "produção capitalista" e capitalismo que, em nossa opinião, é resolvida apenas pela consideração do fechamento espacial operado, em geral, pelas fronteiras dos Estados. Para observar os pontos referenciados, fizemos um breve passeio pela história do Mediterrâneo,nos séculos XIV a XVI, e colocamo-la em correspondência com a análise de Marx, sobre as colônias inglesas. Com base nessa premissa, indagamos sobre a sua implicação na expansão da forma do estado-nação e a funcionalidade que ela teve em diferentes estágios do capitalismo, incluindo uma reflexão sobre a sua função atual.

Palavras-chave: Espaço, Marxismo, Estado, nação.

Recebido: Junho 2018

Aceitado: Julho 2018

\section{RESUMEN}

Este artículo pretende ser una modesta contribución a la antigua y nunca totalmente resuelta polémica acerca del papel del espacio en la teoría de Marx, entendiendo que existe, de manera implícita, un potente análisis del espacio geográfico en los últimos dos capítulos del primer tomo de El capital. Allí aparece una tensión entre "producción capitalista" y capitalismo que, a nuestro juicio, se zanja solo por la consideración de la clausura espacial operada, en general, por las fronteras de los Estados. Para observar ello hacemos un breve recorrido por la historia del Mediterráneo en los siglos XIV al XVI, y lo ponemos en correspondencia con el análisis de Marx sobre las colonias inglesas. A partir de dicha premisa indagamos sobre su implicancia en la expansión de la forma Estado-nación, y la funcionalidad que el mismo ha tenido en distintas etapas del capitalismo, incluyendo una reflexión sobre su función actual.

Palabras clave: Espacio, Marxismo, Estado, nación.

\footnotetext{
${ }^{1}$ Dr. en Ciencias Sociales. Investigador de la Universidad de Buenos Aires y del Consejo Nacional de Investigaciones Científicas y Técnicas (CONICET). Buenos Aires, Argentina. Correo electrónico: flabian.nievas@gmail.com
} 


\begin{abstract}
This article aims to be a modest contribution to the old and never fully resolved polemic about the role of space in Marx's theory, understanding that there is, implicitly, a powerful analysis of the geographical space in the last two chapters of the first volume of Capital. There appears a tension between "capitalist production" and capitalism that, in our opinion, is settled only by the consideration of the spatial closure operated, in general, by the borders of the States. To observe this we make a brief tour through the history of the Mediterranean in the XIV to XVI centuries, and we put it in correspondence with Marx's analysis of the English colonies. Based on this premise, we inquired about its implication in the expansion of the nation-state form, and the functionality that it has had in different stages of capitalism, including a reflection on its current function.
\end{abstract}

Key Words: Space, Marxism, Nation, State.

\title{
INTRODUCCIÓN
}

Se ha debatido acerca de la importancia que Marx asignaba al espacio en sus análisis sobre el capitalismo, sin arribar a un acuerdo este asunto. Los más interesados en dilucidar esto han sido geógrafos que se identifican dentro de esta tradición intelectual, pero sin conciliar posiciones. El fundador de la prestigiosa revista Herodote sostiene que hay "que comprobar en primer lugar el silencio, el «vacío» respecto a los problemas espaciales que caracteriza la obra de Marx." (Lacoste, 1977, p. 81). En oposición, Massimo Quaini encuentra en dicha obra los fundamentos de una "geografía subversiva" (Quaini, 1981, p. 155-97), aunque sus argumentos son más filosóficos que geográficos. Más productiva parece la defensa que hace de tal postura David Harvey, en su comparación en el tratamiento del espacio entre Hegel, von Tünen y Marx (Harvey, 2007ª p. 303-31), aunque en su vasta obra hay muchas referencias y desarrollos parciales que conjugan, en su totalidad, la tesitura de que no habría una teoría acabada de la espacialidad en los escritos de Marx, pero sí los elementos necesarios para conformarla. En este artículo se quiere llamar la atención sobre un aspecto que generalmente es pasado por alto, tanto en dicho debate, como en general dentro de la cultura marxista y geográfica, con directa repercusión sobre otro importante punto "oscuro" en la obra del Marx: el Estado, a cuyo tratamiento se había 
Marx, el espacio geográfico y el Estado.

propuesto dedicar uno de los originalmente seis libros en que pensaba dividir El capital, pero que finalmente jamás escribió. ${ }^{2}$

En el muy conocido capítulo XXIV del libro primero de El capital, sobre la acumulación originaria, Marx desecha el análisis de la sociedad medieval para dedicarse de lleno al examen de los procesos que, combinados, dieron origen al capitalismo. Alli advierte que "[a]unque la producción capitalista, esporádicamente, se estableció ya durante los siglos XIV y XV en los países del Mediterráneo, la era capitalista sólo data del siglo XVI." (Marx, 1987, I:p. 924). Este señalamiento ordinariamente se pasa por alto 0 , al menos, no ha concitado la atención que se merece, ${ }^{3}$ ya que del mismo surgen tres cuestiones: la primera es que si bien el capitalismo requiere de producción capitalista, ésta no conforma por sí misma al capitalismo, es decir, el capitalismo existe como sistema cuando dicha producción genera un entramado que imprime su dinámica al conjunto de la sociedad considerada, incluidos aquellos sectores que son ajenos a tal tipo de producción. ${ }^{4}$ De allí se deriva la segunda cuestión, que es ¿qué factores o elementos diferenciales operan en una u otra situación, es decir, en la que existe producción capitalista sin capitalismo como forma predominante de producción, y aquella en que, por el contrario, se instala en el capitalismo? Finalmente, la tercera cuestión que surge de las anteriores, y ya vinculada al desarrollo histórico efectivo, es que parece lícito preguntarse por qué, si la producción capitalista se puede encontrar uno o dos siglos antes en los países del Mediterráneo, el sistema capitalista no surge de allí, sino en Gran Bretaña.

\footnotetext{
${ }^{2}$ Rosdoslky realizó un trabajo erudito (1989) de comparación entre los borradores originales de El capital (conocidos como Grundrisse) y lo finalmente publicado, en el marco del plan original de 1857 y el resultante de 1865.

${ }^{3}$ Incluso Dobb, en su gran obra sobre el origen del capitalismo, sólo menciona este pasaje en un pie de página para decir que "podría haber agregado Flandes y el distrito renano" (Dobb, 1987: 155), lo cual es cierto, y se podrían sumar algunos centros más pero, como veremos, no varía sustancialmente la cuestión. Tampoco mencionan este aspecto los críticos de Dobb en la polémica surgida tras la aparición de su libro, a mediados del siglo pasado. (cf. Sweezy et. al., 1974).

4 "Las mercancías que ingresan en el proceso de circulación del capital industrial (entre las que se cuentan también los medios de subsistencia necesarios en los que se convierte el capital variable luego de ser pagado a los obreros, a efectos de que la fuerza de trabajo se reproduzca), sea cual fuere su origen, la forma social del proceso de producción del cual surgen, se enfrentan ya al propio capital industrial bajo la forma de capital mercantil, bajo la forma de capital dedicado al tráfico de mercancías o capital comercial; pero éste abarca, por su naturaleza, mercancías provenientes de todos los modos de producción." (Marx, 1987, II: 130, destacado nuestro).
} 
La respuesta directa a tal interrogante no aparece allí ni en ninguna parte de la obra, pero los elementos para la misma están en el capítulo siguiente, a menudo menospreciado por los especialistas. ${ }^{5}$

\section{EL ESPACIO Y EL SURGIMIENTO DEL CAPITALISMO}

\section{La cuestión del espacio}

En el último capítulo Marx toma la teoría de la colonización de Edward Gibbon Wakefield, en boga en ese momento, no solo para una deconstrucción lúcida de la misma, sino para terminar de presentar un elemento que está desperdigado a lo largo de El capital. Creo que Marx era consciente de la importancia -al menos en el aspecto que señalaré- del espacio y por ello decide explicitarlo e incluirlo al final de su trabajo.

Allí afirma que

Wakefield descubrió en las colonias que la propiedad de dinero, de medios de subsistencia, máquinas y otros medios de producción no confieren a un hombre la condición de capitalista si le falta el complemento: el asalariado, el otro hombre forzado a venderse voluntariamente a sí mismo. Descubrió que el capital no es una cosa, sino una relación social entre personas mediada por cosas (Marx, 1987, I: p.957).

Se trata, indudablemente, de un señalamiento fuerte, ya que confronta la visión vulgar del capital como cosa, y la expone como una relación social, es decir,

\footnotetext{
${ }^{5}$ En la publicación en castellano de El capital de Siglo XXI, que es lo que más se aproxima a una edición crítica ya que compone las variantes de las cinco ediciones originales (las primera y segunda, al cuidado de Marx, tercera y cuarta con modificaciones e incorporaciones de Engels, todas ellas en alemán, más la edición en francés, publicada con la supervisión de su autor), los editores incorporan una pos-nota al final del capítulo XXIV, en la que recogen una variante introducida por Maximilien Rubel en su edición de CEuvres de Marx. El austro-francés alteró el orden de los capítulos finales de El capital (que, en su versión francesa consta de treinta y dos capítulos, debido a que se presentan como tales cada uno de los siete parágrafos de lo que en la versión alemana es el capítulo XXIV), poniendo el capítulo XXV (32 en la versión francesa original) como anteúltimo, y el §.7 del capítulo XXIV (versión alemana, 31 en la francesa original) como último, debido a que, especulaba este editor ( $\mathrm{y}$ los editores en esta versión castellana le dan verisimilitud a tal hipótesis), esa es la ubicación lógica del mismo, pero que no pudo ser publicado así originalmente motivado en la necesidad de eludir la censura (cf. Marx, 1987, I: 1085-6). Esta alteración menoscaba la impronta teórica del capítulo XXV original, el que resulta tratado como un trasto viejo que no se sabe muy bien dónde ubicar, pero que en algún lado hay que poner. Sumamente llamativa es la casi omisión de este capítulo en el prestigioso curso sobre el tomo I de El capital de David Harvey (2014). El índice concluye en el tratamiento del capítulo XXIV, no obstante, en el interior de dicho apartado le dedica menos de dos carillas a presentar sumariamente el capítulo XXV, aunque sin merecer ninguna reflexión particular.
} 
Marx, el espacio geográfico y el Estado.

como un proceso, como una particular forma de vinculación entre las personas. Inmediatamente pasa a relatar la situación de un tal señor Peel, quien hizo una inversión en Australia de $£ 50.000$ en medios de subsistencia y de producción, trasladando además a 3.000 personas, que eran obreros con sus familias. Al poco tiempo de arribar, los obreros se habían convertido en colonos y abandonado al señor Peel y la relación salarial. Por ello, con sorna, exclama: "Infortunado señor Peel, que todo lo había previsto, menos la exportación de las relaciones de producción inglesas". Un panorama similar se daba en Estados Unidos:

La caudalosa y continua correntada humana que año tras año fluye hacia Norteamérica, en parte deposita sedimentos estacionarios en el Este de Estados Unidos; en parte, la ola emigratoria procedente de Europa arroja hombres allí, en el mercado de trabajo, más rápidamente de lo que puede barrerlos la ola emigratoria que los empuja hacia el Far West. La producción capitalista, pues, prospera en los estados del Este, aunque la baja de salarios y la dependencia del asalariado disten todavía de haber alcanzado los niveles normales en Europa (Marx, 1987, I: p. 966).

En ambos casos el problema que está indicando Marx es la falta de fronteras fijas e inviolables, que es lo que impide el establecimiento de las "relaciones de producción inglesas", es decir, las relaciones sociales capitalistas. Y este es el punto que hay que enfatizar: cuando Marx dice que "el capital no es una cosa, sino una relación social entre personas mediada por cosas", rompiendo con la concepción fetichista de considerar capital a una suma de dinero o a las instalaciones productivas, hay que pensar que la relación social, como tal, no es solamente la forma de vinculación entre personas mediadas por cosas (o, en una sociedad capitalista, por dinero, equivalente universal de las cosas-mercancías), sino que entre las condiciones de posibilidad para hacer efectivas, estables y generalizadas tales relaciones, se debe considerar una determinada configuración espacial, que es la clausura, o delimitación territorial. Esta es la clave interpretativa: sólo en un espacio clausurado es posible la estabilización de estas relaciones sociales. Esto se corrobora -aquí radica la importancia- en Inglaterra, que es una isla. Y falta, justamente, en las ciudades mediterráneas. 


\section{La isla}

Fue Carl Schmitt quien llamó la atención sobre el carácter insular inglés como el aspecto peculiar que le daba tal atributo a su historia. ${ }^{6}$ Esta es, justamente, la singularidad de Gran Bretaña respecto tanto de Estados Unidos, Australia y las ciudades mediterráneas. A diferencia de todos estos casos, la población británica tenía fronteras fijas, infranqueables naturalmente. El hecho de ser una isla, un territorio rodeado por mar, hizo que los procesos desatados involucraran necesariamente a los grupos poblacionales afectados, para quienes el desplazamiento era una opción limitada, ya que, llegados a un punto, no había más espacio libre de tales procesos al que trasladarse. Esto explica la viabilidad de la "legislación sanguinaria": las espantosas penalidades reseñadas por Marx sólo podían efectivizarse si las víctimas de ellas carecían de una movilidad ilimitada o, al menos, bastante amplia. La clausura espacial operó hasta bien avanzada la instalación de las relaciones capitalistas. Marx señala que, en el siglo XVIII, la expulsión de los gaélicos estuvo acompañada por la prohibición de emigrar, y aún en el siglo XIX la duquesa de Sutherland empujó a unos 15.000 gaélicos contra el mar (Marx, 1987, I: p. 912-914), a quienes, es evidente, que no les quedó otra opción que ingresar en las relaciones capitalistas. También recuerda que no era ello una novedad, pues habían existido "procesos anteriores de índole similar". Si se abstraen los espantosos detalles de los hechos, lo que queda de manera evidente es la variable espacial como el factor que hace posible el desarrollo del proceso.

Sería osado afirmar que el factor espacial es la clave única para explicar el surgimiento del capitalismo industrial en las islas británicas y no en las ciudades mediterráneas; pero también sería osado ignorar este factor como una (y no la menos importante) de las condiciones necesarias para que se desarrollase tal

\footnotetext{
6 "Es claro que Inglaterra es una isla. Pero con determinar este hecho geográfico no se dice gran cosa. [...] Vimos ya la transformación que supone el que un pueblo de pastores se convirtiese, al filo del siglo XVI, en un pueblo de hijos del mar. Tal fue la evolución fundamental de la esencia histórico-política de la propia isla." Schmitt 2007, p. 70-71.
} 
Marx, el espacio geográfico y el Estado.

proceso. No obstante, es necesario observar lo que ocurría en los Estados italianos en la época señalada por Marx como antecedente del capitalismo.

\section{La producción capitalista en los países del Mediterráneo}

El Mediterráneo fue, desde la Antigüedad, una zona de intenso tránsito mercantil, uniendo desde el extremo este de Europa (Hispania) con Asia Menor, el norte de África y la región balcánica. Aunque los pueblos prehistóricos ya lo surcaban, fue el mare nostrum romano el que permitió un comercio importante y estable. No obstante, es altamente probable que su volumen comercial fuera bastante menor al de otras regiones, en particular al desarrollado en China e India, como fue en las primeras etapas del capitalismo. ${ }^{7}$ Tras la expansión musulmana a partir del siglo VII, los cristianos recuperaron el control del Mediterráneo, en parte por el impulso de las Cruzadas, y en parte por la tracción del comercio marítimo, que nunca había prescindido de la expertise de los navegantes cristianos (sobre todo genoveses, venecianos y, luego, también catalanes). Hacia el siglo XIV se había estabilizado la región, con una fuerte presión demográfica y un intenso tráfico mercantil. Esta situación cambió radicalmente sobre fines de la primera mitad de la centuria con la peste bubónica, o peste negra, llegada a través de Asia y Europa oriental, y extendiéndose hacia el interior de Europa, eliminando a un tercio de su población en el período 1346-1350 (McNeill, 1984, p. 162-166). Esto produjo un drástico reordenamiento económico. Después de la peste negra

Las nuevas actitudes mentales dieron lugar a la aparición de nuevas estructuras. La creciente especialización, reflejada en el crecimiento de los gremios artesanales, y también la migración a las ciudades de campesinos, cuyos pueblos habían dejado de funcionar debido a la falta de mano de obra, estimularon la vida urbana (Abulafia, 2013, p. 391-392).

\footnotetext{
7 "En 1500 [...] aunque el eje de las redes afroeuroasiáticas de intercambio estuviera en el suroeste asiático, el centro de gravedad estaba en China y la India. El tráfico que pasaba por el Mediterráneo oriental sería más variado y procedería de una región más amplia, pero el volumen que circulaba por Asia oriental era el más elevado." Christian, 2005, p. 447. "[...] desde por lo menos 1400 hasta 1800, Asia fue la parte económicamente más avanzada del mundo. [...] Hace tan sólo doscientos años eran [...] India y China, los que concentraban dos tercios de la producción económica mundial”. Marks, 2007,p. 12 y 14. Cf. Braudel, 1984, III: p. 406.
} 
La vida urbana, por su dependencia de los productos agrícolas para el sostenimiento de sus poblaciones, impulsa el comercio. Pero el volumen comercial de las ciudades mediterráneas no se explica por su desarrollo urbano, sino por ser ellas los nodos que articulaban el intercambio euro-afro-asiático. Conformaban el núcleo del capitalismo comercial, cuyo dinamismo se centra en la circulación. Marx consideraba al capital comercial como pródromo del capitalismo industrial.

El capitalismo comercial no excluye, por supuesto, la producción industrial —amén de que tampoco extrae el plusvalor del mero intercambio-, pero no es esta quien impone el ritmo social, sino que, por el contrario, la producción industrial acompaña al desarrollo comercial y es acompasada por éste. Para romper esta subordinación de la industria al comercio fue necesario que ocurrieran sucesos relativamente extraordinarios —no en sí mismos, sino por su concurrencia espacio-temporal- que alteraran la homeorresis, ${ }^{8}$ posibilitando la emergencia de una nueva configuración.

Las ciudades mediterráneas se asentaban en un espacio abierto, que potenciaba la circulación, tanto por el mar como por la tierra. Si bien la península itálica está surcada por los Apeninos, Braudel señala que las mismas no operaban como barrera, sino que estaban integradas a la economía mercantil. ${ }^{9}$ Esta integración entre la economía capitalista mercantil y las economías de autoconsumo dificultaba la formación de un proletariado en sentido pleno; a diferencia de lo que ocurriría en Gran Bretaña en el siglo XVI, aquí los trabajadores asalariados gozaban, de vez en cuando, de alternativas de vida. Entre muchas otras, las endémicas guerras convocaban a mercenarios para que lucharan en las filas de uno u otro señor o reino, lo que se lograba reclutando tanto campesinos pobres como aquellos que, reacios a seguir la vida en ocasiones miserable del incipiente proletariado, se decidían a incorporarse en algunas de estas compañías. También podían, eventualmente, subirse a los barcos y hacerse marineros de

\footnotetext{
${ }^{8}$ La homeorresis indica un equilibrio dinámico temporal e histórico, procesual, a diferencia de la homeostasis, que denota un equilibrio dinámico final.

${ }^{9}$ [...] estas montañas dirigen su emigración, naturalmente, hacia el mar, [...] Se establece, pues, una asociación entre la vida marítima, por una parte, y la economía montañesa, por la otra. Ambas se influyen y se complementan. De ahí la asombrosa asociación de la labranza, los huertos y la pesca, es decir, de la vida agrícola y marinera." Braudel, 2013, I: p. 188.
} 
Marx, el espacio geográfico y el Estado.

manera definitiva, o solo para trasladarse a otro punto a buscar fortuna. Pero, por sobre todo, más que evaluar las alternativas de salirse de las relaciones capitalistas, lo que nos importa poner en evidencia es la capacidad de los sectores social y económicamente más débiles para sustraerse a ingresar a tales relaciones. Todas estas grandes ciudades mediterráneas estaban rodeadas por campiñas, de mayor o menor extensión, en las que aún podían subsistir sin necesariamente estar anclados en vínculos feudales, los que en mayor o menor medida, según la región, se estaban volviendo más laxos. Así, por ejemplo, en las lagunas venecianas subsistían pescadores artesanales, así como pequeños productores agrícolas en sus inmediaciones. ${ }^{10}$ Aunque la riqueza generada por el comercio era sin dudas un importante atractivo para la población periférica, también es cierto que las industrias carecían de capacidad para absorber a su totalidad. Existía, de tal modo, una suerte de equilibrio entre formas capitalistas, formas feudales y formas transicionales que no corresponden plenamente a ninguna de las dos clasificaciones anteriores. ${ }^{11}$

Esta funcionalidad fue posible debido cæteris paribus a la apertura espacial, es decir, a la posibilidad efectiva de circulación sin restricciones, fenómeno potenciado por la multiplicidad de unidades políticas en la península itálica, que conformaban, en su conjunto, un sistema de pequeños Estados relativamente débiles. ${ }^{12}$ El factor espacial puede ser considerado, razonablemente, como el desencadenante no sólo del proceso de acumulación originaria, sino también de la expansión de la forma Estado-nación, como expondré seguidamente.

\footnotetext{
10 "Hacia 1530, el Aretino, que tenía una mansión situada sobre el Canal Grande, se entretenía observando las barcas cargadas de frutas y de montañas de melones procedentes de las islas de la laguna y que acudían a este «vientre» de Venecia". Braudel, 2012,p. 28.

11 "Por un lado, están los campesinos en sus pueblos, que viven de forma casi autónoma, prácticamente autárquica; por otro, una economía de mercado y un capitalismo en expansión [...]. Hay, por lo menos, dos universos, dos géneros de vida que son ajenos uno al otro". Braudel, 2012, p. 11-12.

${ }_{12}$ Hacia el siglo XV encontramos el reino de Sicilia, el de Nápoles, el de Cerdeña, Córcega, los Estados Papales, la República de San Marino, la de Lucca, la de Génova, la de Venecia, el Gran Ducado de Toscana, los Ducados de Saboya, de Milán, de Parma, de Módena, de Massa, de Ferrara, los Marquesados de Saluzzo, del Monferrato. Asimismo debe considerarse un segundo factor, también espacial, en el debilitamiento de la economía itálica: "Parte de la explicación reside en el hecho de que el Atlántico tomó el testigo como eje del comercio mundial, y en la creciente importancia del comercio con los países mediterráneos." Duggan, 2017,p. 83.
} 


\section{EL ESTADO-NACIÓN (EXPANSIÓN Y CONSOLIDACIÓN DEL CAPITALISMO)}

La forma "Estado-nación" puede considerarse relativamente anómala, toda vez que, en su peculiar asociación entre un aparato jurídico-político y algo relativamente inasible, como la nación, podría haber sido una solución precaria y singular para una situación específica (Tilly, 1993, p. 21). ${ }^{13}$ Pero no ha sido este el caso, dado que esta forma se extendió desde Europa hacia el resto del planeta (Langewiesche, 2012, p. 25).

Es sumamente estimulante el ya clásico trabajo de Charles Tilly Coerción, capital y los Estados europeos. 990-1990, más por las preguntas que se hace que por las respuestas que ofrece. La pregunta nuclear es “¿qué explica [...] y por qué convergieron al fin los Estados europeos en diversas variantes del Estado nacional?" (1993, p. 62). Si esa gran pregunta es válida para Europa, que es donde surgió la forma Estado-nación, mucho más lo es para el resto del globo, donde fue implantada dicho formato, sin otro antecedente que la experiencia europea.

Tilly da una serie de razones históricas y teóricas para explicar la primacía de esta forma por sobre otras (imperios, ciudades-Estado, federaciones de ciudades, Estados absolutistas, Estados pontificios, ducados, principados, etc.), en su mayoría atendibles, que están ligadas a la concentración de capital, por un lado, y a la capacidad de coerción, por otro. El argumento deja de ser satisfactorio cuando uno se pregunta qué entiende Tilly por "capital", ya que nada dice al respecto, y el uso del término hace pensar que es la noción vulgar de dinero y/o bienes criticada por Marx.

Por otra parte, el estudio de Tilly se circunscribe a Europa; sin embargo, esta forma se extendió por todo el globo. La primera evidencia es que siguió, más o menos, el ritmo de la expansión capitalista, lo que induce a que resulte ineludible

\footnotetext{
13"De todas las diversas formas de sistemas políticos y económicos que los seres humanos habían experimentado para obtener el sustento de la tierra y aumentar sus poblaciones, el de mayo éxito era, con mucho, el imperio. Tanto que merece la pena reflexionar la razón por la que no vivimos hoy en un imperio en lugar de hacerlo en naciones-estado. La respuesta es que en Europa occidental se desarrolló un nuevo sistema de estados." Marks, 2007, p. 102.
} 
Marx, el espacio geográfico y el Estado.

pensar en una eventual vinculación entre ambos fenómenos, ${ }^{14} \mathrm{o}$ bien pensarlo como dos aspectos de un mismo fenómeno.

Desde la hipótesis que estamos planteando, resulta congruente pensar en la nueva forma como un dispositivo de oclusión espacial que permitía el afianzamiento del nuevo orden económico social toda vez que: a) fijaba fronteras relativamente estables, consustancial a la fijación de las poblaciones; $b$ ) desarrollaba y consolidaba mercados nacionales, que son el soporte del mercado mundial, indispensable para la expansión capitalista; $c$ ) inauguraba un nuevo registro de legitimidad (la ciudadanía) que, además, ocultaba las diferencias sociales resaltando la igualdad jurídica de la población adulta de cada país, es decir, enfatizando los mecanismos de mercado (ámbito de realización de los equivalentes) por sobre los de producción (ámbito de las diferencias sociales). ${ }^{15}$ Lo señalado en el ítem a es la condición necesaria para $b$ y $c$.

Marx brinda dos argumentos sobre la fijación de las poblaciones obreras. Uno es la disponibilidad de fuerza de trabajo, pues una parte componente del capital es la sección variable del mismo, cuya desnaturalización se manifiesta en las crisis. ${ }^{16}$ La segunda cuestión es la diversidad nacional de los salarios (tratada en el cap. Xx del primer tomo de El capital), es decir, la posibilidad del capital de

\footnotetext{
14“[...] el desarrollo de las naciones-estado como forma de organización política en Europa se produjo por razones bastante independientes de las que condujeron a la industrialización. Sin embargo, cuando ambos procesos convergieron durante el siglo XIX, la coyuntura permitió que se desarrollara una poderosa fuerza global cuando ambos procesos proporcionaron la base para el dominio militar." Marks, 2007, p. 30.

${ }^{15}$ Habida cuenta de la deslegitimación de las formas absolutistas, era necesario una nueva forma de aceptación de este ordenamiento político. El nuevo dispositivo requería de la creación de un nuevo mito, la "nación".("En tiempos de Mazzini no importaba que para el grueso de los italianos el Risorgimento no existiera, tal como reconoció Massimo d'Azeglio en la famosa frase: "Hemos hecho Italia, ahora tenemos que hacer los italianos". [...] el futuro liberador de Polonia, el coronel Pilsudski, reconoció en su frase: "Es el estado el que hace la nación y no la nación el estado»." Hobsbawm, 2012, p. 53). Este dispositivo ideológico, curioso y osado en su puesta en funcionamiento, que requiere verdaderamente de "inventar tradiciones" (cf. Hobsbawm y Ranger, 2002), una vez establecido se solidifica con la firmeza de una roca, al punto de constituir un rasgo identitario para la población comprendida por dicha "nación". Esas parecieran ser las cuestiones que operan en la base de la expansión de esta forma de organización territorial. Por ello, si la nación falla, el Estado colapsa (Nievas y Sampó, 2016).

16 "Hasta qué punto el capitalista cuenta, entre las condiciones de producción que le pertenecen, con la existencia de tal clase obrera diestra, considerándola de hecho como la existencia real de su capital variable, es una circunstancia que sale a luz no bien una crisis amenaza la pérdida de aquélla." (Marx, 1987, I: p. 706) A continuación transcribe y analiza el "manifiesto de los fabricantes" de 1863, por la cual se demandaba que no se permita la emigración de los obreros del algodón en paro (Marx, 1987, I: p. 707-711).
} 
contar con costos diferenciales de la fuerza de trabajo, lo que permite de manera permanente la relocalización de la producción, siendo ésta una manera de librar la lucha de clases: frente a una clase obrera (nacional) que cobra fuerza (cuya medida se observa en el salario real), el capital simplemente se desplaza. ${ }^{17}$ Este argumento contiene numerosas aristas que han sido oportunamente desarrolladas en diversos trabajos por el geógrafo David Harvey, pero cuyo núcleo está en la diferenciación territorial, es decir, en la segmentación y compartimentación espacial, con contornos definidos, y con particularidades que hacen de cada territorio una organización social y conceptual de cada espacio, como forma emergente de un conjunto de relaciones sociales (Nievas, 1994, p. 77).

La organización conceptual no es algo menor: debe haber un reconocimiento del territorio, una apropiación cuyo fundamento emotivo permita construir argumentos en pos de justificar su existencia. En Europa, el naciente capitalismo mercantil se asentaba en una forma aún feudal de Estado, dado por el absolutismo. Los Estados absolutistas tenían un fundamento divino: el monarca lo era por gracia de dios -incluso en algunos casos, era un semi-dios, como lo fueron los zares de la dinastía Romanov-. Pero esos fundamentos cayeron junto a la testa de Luis XVI. Aunque las monarquías europeas se abroquelaron tras la derrota de Napoleón, conformando en Viena una alianza reaccionaria, el absolutismo ya había muerto. Era la hora de las naciones. Con el fundamento de legitimidad en el pueblo, la nación era el artefacto cultural que de algún modo sustituía, tal vez con mayor eficacia, al anterior artefacto religioso (Anderson, 2016, p. 29-30).

El sistema interestatal en el que funciona el modelo de Estado-nación es anterior al surgimiento del mismo, en pleno apogeo del absolutismo, con los Tratados de Paz firmados en Westfalia en 1648. Casi inmediatamente, en 1651, Thomas Hobbes publica su Leviatán (Hobbes, 1992) dando fundamentos laicos al

17 "La acumulación de capital siempre ha sido una cuestión profundamente geográfica. Sin las posibilidades inherentes a la expansión geográfica, la reorganización espacial y el desarrollo geográfico desigual, hace tiempo que el capitalismo habría dejado de funcionar como sistema político y económico." Harvey, 2007b,p. 38. 
Marx, el espacio geográfico y el Estado.

Estado, lo cual indica el comienzo del declive de la legitimidad dinástica fundada en la religión.

La convergencia histórica de estos procesos de orígenes variados proporciona una condición necesaria, aunque no suficiente, para el establecimiento y expansión del capitalismo industrial, cuya organización no fue posible sin clausurar el espacio para contener a la población a la que se le liquidaban las formas pretéritas de vida, compeliéndolas a ingresar en la posición subordinada de las relaciones capitalistas de explotación. Por otra parte, la constitución de estas unidades políticas —cada una de ellas expresión de un territorio organizado por la dominación de un grupo burgués que devendrá, consecuentemente, en "burguesía nacional" - se instituye como modelo "racional" y "civilizado", es decir, ideológicamente legítimo y deseable, pero que es consustancial al funcionamiento del capitalismo industrial. ${ }^{18}$ La potencia de esta expansión fue tal que se impuso en todo el globo, pese a ser una forma surgida de la peculiar historia europea. En América, África y Oceanía, claramente los Estados formaron naciones. En Asia, en cambio, hay expresiones nacionales incluso antes que en Europa. Esto significa que no se puede hacer una historia de los Estados nacionales, sino que cada región tiene sus especificidades. Lo que sí se puede aseverar es que su expansión ha sido concomitante con la propagación y consolidación del capitalismo industrial.

\section{DESPUÉS DEL CAPITALISMO INDUSTRIAL}

Existe amplio consenso en las ciencias sociales en que ya no vivimos en un capitalismo industrial, lo que no significa, por supuesto, que las industrias hayan mermado en importancia. Lo que se significa con esto es que el dinamismo social ya no está impuesto por el sector industrial. Crecientemente desde el último tercio del siglo pasado, es el sector financiero el más dinámico y el de mayor acumulación, gran parte de la cual escapa a toda contabilidad pública.

\footnotetext{
${ }^{18}$ La teoría marxista elaboró la categoría de "personificación" para dar cuenta de la presentación subjetiva de necesidades funcionales.
} 
Una nueva forma del dinamismo capitalista requiere un redimensionamiento del espacio, lo que Carl Schmitt Ilamaba "revolución espacial" (2007, p. 48-49). Sin necesidad de aventurar hipótesis sobre la forma de constitución de la nueva espacialidad, es fácilmente constatable la merma de poder de los Estados-nación frente a organismos multilaterales, corporaciones privadas, organizaciones no gubernamentales, y nuevos sectores que escapan a cualquier encuadre, la lumpenburguesía. $^{19}$ El Estado-nación aún sigue cumpliendo importantes funciones, necesarias para el sostenimiento del capitalismo, pero ya no son las mismas que lo hicieron surgir. La aparición de compañías militares privadas torna obsoleta la definición weberiana de Estado. Las políticas intervencionistas bajo invocaciones humanitarias socavan abiertamente la soberanía estatal. $Y$ todo esto se hace con la anuencia de los propios Estados. Igualmente significativo es la proliferación de una red espacial de evasión fiscal, los llamados "paraísos fiscales", que operan como un espacio paralelo al estatal, aunque se trate en algunos casos de Estados o estén dentro de ellos.

Debemos considerar, además, la apertura de una nueva dimensión, que es el ciberespacio, por la que discurre la mayor parte de la actividad financiera mundial. El ciberespacio carece de fronteras y de regulaciones, razón por la que debe considerárselo como parte de la totalidad social y observar la forma en que afecta la espacialidad "tradicional", las dimensiones en las que existimos físicamente. Un estudio de la espacialidad del capitalismo financiero debe incluir necesariamente esta nueva dimensión.

\section{CONCLUSIÓN}

Comprender de manera cabal el cambio implica reconocer la revolución espacial en marcha, para lo cual las indicaciones de la teoría marxista constituyen un buen instrumento conceptual. Paradójicamente, pese a que Marx abandonó su proyectado libro sobre el Estado (Rosdolsky, 1989, p. 39), hoy resulta de suma importancia recuperar sus estructuras analíticas para tener una mejor

\footnotetext{
${ }^{19}$ No le doy la misma significación que Gunder Frank (1972), como burguesía subdesarrollada y neocolonial, sino acentuando su aspecto lumpen: andrajosa, marginal, evasora de impuestos; típicamente, la dedicada al tráfico de estupefacientes, pero también de armas, personas, etc.
} 
Marx, el espacio geográfico y el Estado.

comprensión del devenir de un sistema social que, pese a las variaciones históricas respecto del momento en que él escribió, en lo medular no ha cambiado: el capitalismo sigue produciendo en esencia y ante todo, plusvalor.

En tanto la médula es la misma, la lógica sobre la que opera resulta también invariante; lo que cambian son las formas y las dinámicas que se imprimen al proceso. Pero el fenómeno puede seguir siendo abordado con las categorías analíticas del marxismo. Particularmente en una fase transicional, como la que vivimos, en la cual el ordenamiento espacial parece estar mutando de forma, y la arquitectura y funcionalidad del Estado-nación ha dejado de ser lo que originalmente era y se constituye en algo novedoso. Esto suele provocar confusiones, y es fácil tentarse por novedades teóricas. Pero las pruebas que ponen el tiempo y las coyunturas a los artefactos teóricos son los mejores jueces para validar o invalidarlos. He intentado demostrar que el marxismo es un instrumento potente para el análisis de la forma Estado-nación en su forma tradicional. Sería necesario mirar más de cerca los análisis que Engels compiló en el libro II de El capital para encontrar algunas claves de las formas que se van constituyendo actualmente, aunque no tengamos certezas porque tales formas no se han consolidado aun.

Esta sugerencia no significa afirmar que los análisis realizados por Marx no requieran revisión, sino, más bien, seguir sus razonamientos, observar su lógica, que es lo que, en definitiva, sigue teniendo actualidad.

\section{REFERENCIAS BIBLIOGRÁFICAS}

Anderson, Benedict (2016). Comunidades imaginadas. Fondo de Cultura Económica. México.

Abulafia, David (2013). El gran mar. Una historia humana del Mediterráneo. Crítica. España.

Braudel, Fernand (1984). Civilización material, economía y capitalismo, siglos XV-XVIII. Alianza. España.

Braudel, Fernand (2012). La dinámica del capitalismo. Fondo de Cultura Económica. México.

Braudel, Fernand (2013). El Mediterráneo y el mundo mediterráneo en la época de Felipe II. Fondo de Cultura Económica. México.

Christian, David (2005). Mapas del tiempo. Introducción a la "gran historia". Crítica. España. 
Dobb, Maurice (1987). Estudios sobre el desarrollo del capitalismo. Siglo XXI. México.

Duggan, Christopher (2017). Historia de Italia. Akal. España.

Gunder Frank, André (1972). Lumpenburguesía: lumpendesarrollo. Dependencia, clase y política en América Latina. Laia. España.

Harvey, David (2007a). Espacios del capital. Akal. España.

Harvey, David (2007b). Espacios de esperanza. Akal. España.

Harvey, David (2014). Guía de El Capital de Marx. Libro primero. Akal. España.

Hobbes, Thomas (1992). Leviatán, o la materia, forma y poder de una república eclesiástica y civil. Fondo de Cultura Económica. México.

Hobsbawm, Eric (2012). Naciones y nacionalismo desde 1780. Crítica. España.

Hobsbawm, Eric y Ranger, Terence (2002). La invención de la tradición. Crítica. España.

Lacoste, Yves (1977). La geografía: un arma para la guerra. Anagrama. España. Langewiesche, Dieter (2012). La época del Estado-nación en Europa. Universitat de Valencia. España.

Marks, Robert (2007). Los orígenes del mundo moderno. Una nueva visión. Crítica. España.

Marx, Karl. (1987). El capital. Siglo XXI. México.

McNeill, William (1984). Plagas y pueblos. Siglo XXI. España.

Nievas, Flabián (1994). Hacia una aproximación crítica a la noción de "territorio". Nuevo espacio. Revista de sociología. Año 1, volumen 1. Argentina (pp. 75-92)

Nievas, Flabián y Sampó, Carolina (2016). ¿Estados fallidos? O sobre la imposibilidad de constituir el Estado nación moderno. Revista de relaciones internacionales, estrategia y seguridad. Volumen $11, \mathrm{~N}^{\circ} 1$. Colombia (pp. 103-119)

Rosdoslky, Roman (1989). Génesis y estructura de El capital de Marx (estudios sobre los Grundrisse). Siglo XXI. México.

Schmitt, Carl (2007). Tierra y mar. Trotta. España.

Sweezy, Paul; Dobb, Maurice; Takahashi, H. K.; Hilton, Rodney; Hill, Christopher y Lefebvre, Georges (1974). La transición del feudalismo al capitalismo. Ediciones la Cruz del Sur. Argentina.

Tilly, Charles (1993). Coerción, capital y los Estados europeos. 990-1990. Alianza. Argentina.

Quaini, Massimo (1981). La construcción de la geografía humana. Oikos Tau. España. 